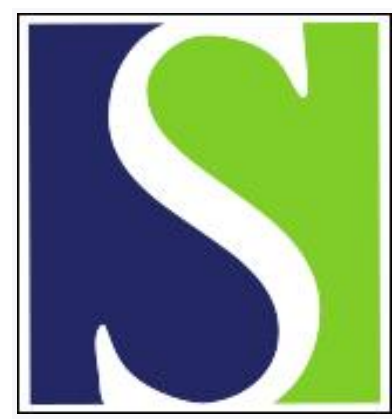

Scand J Work Environ Health 2002;28(6):411-417

https://doi.org/10.5271/sjweh.693

Issue date: Dec 2002

Cancer incidence among workers in the asbestos-cement producing industry in Norway

by Ulvestad B, Kjærheim K, Martinsen JI, Damberg G, Wannag A, Mowé $G$, Andersen A

Affiliation: Cancer Registry of Norway, Institute of Population-based Cancer Research, Montebello, N-0310 Oslo, Norway. bente.ulvestad@kreftregisteret.no

The following article refers to this text: 2004;30(1):64-70

Key terms: asbestos-cement producing industry; asbestos-cement worker; cancer incidence; chrysotile; crocidolite; lung cancer; Norway; pleural mesothelioma; worker

This article in PubMed: www.ncbi.nlm.nih.gov/pubmed/12539801 


\title{
Cancer incidence among workers in the asbestos-cement producing industry in Norway
}

\author{
by Bente Ulvestad, MD, ${ }^{1}$ Kristina Kjærheim, MD, ${ }^{1}$ Jan Ivar Martinsen, ${ }^{1}$ Grete Damberg, MD, ${ }^{2}$ \\ Axel Wannag, MD, ${ }^{3}$ Gunnar Mowe, MD, ${ }^{4}$ Aage Andersen ${ }^{1}$
}

\begin{abstract}
Ulvestad B, Kjærheim K, Martinsen JI, Damberg G, Wannag A, Mowe G, Andersen A. Cancer incidence among workers in the asbestos-cement producing industry in Norway. Scand J Work Environ Health 2002;28(6):411417.

Objectives The incidence of cancer among employees of a Norwegian asbestos-cement factory was studied in relation to duration of exposure and time since first exposure. The factory was active in 1942-1968. Most of the asbestos in use was chrysotile, but for technical reasons $8 \%$ amphiboles was added.

Methods For the identification of cancer cases, a cohort of 541 male workers was linked to the Cancer Registry of Norway. The analysis was based on the comparison between the observed and expected number of cancer cases. Standardized incidence ratios (SIR) and 95\% confidence intervals (95\% CI) were estimated. Period of first employment, duration of employment, and time since first employment were used as indicators of exposure. Poisson regression analysis was used for the internal comparisons.

Results The standardized incidence ratio was 52.5 (95\% CI 31.1-83.0) for pleural mesothelioma, on the basis of 18 cases. The highest standardized incidence ratio was found for workers first employed in the earliest production period (SIR 99.0, 95\% CI 51.3-173). No peritoneal mesothelioma was found. The standardized incidence ratio for lung cancer was 3.1 (95\% CI 2.1-4.3), but no dose-response effect was observed. The ratio of mesothelioma to lung cancer cases was 1:2.

Conclusions This study showed a high incidence of mesothelioma and a high ratio of mesothelioma to lung cancer among asbestos-cement workers. The high incidence of mesothelioma was probably due to the fact that a relatively high proportion of amphiboles was used in the production process.
\end{abstract}

Key terms asbestos-cement workers, chrysotile, crocidolite, lung cancer, pleural mesothelioma.

As early as the 1950s and 1960s, evidence from studies conducted in several countries indicated that workers exposed to asbestos were at risk of developing asbestosis, malignant mesothelioma, and lung cancer (1-3). Asbestos is defined as the fibrous form of mineral silicates belonging to the serpentine and amphibole groups of rock-forming minerals, including actinolite, amosite (brown asbestos), anthophyllite, chrysotile (white asbestos), crocidolite (blue asbestos), tremolite, and a mixture containing one or more of these. Generally, the manufacture of asbestos-cement products has consumed a sizeable proportion of asbestos in use; in Norway around $70 \%$ of the asbestos imported was used in this industry. Chrysotile has been the dominant form of asbestos in the production of asbestos-cement. Follow-up studies of asbestos-cement workers have shown them to be at risk of asbestosis (4). Studies on cancer mortality and incidence have, however, produced variable results.

In several cohort studies of asbestos-cement workers, no elevated mortality from lung cancer or malignant mesothelioma was found (5-8). The authors' main

1 Cancer Registry of Norway, Institute of Population-based Cancer Research, Montebello, Oslo, Norway.

2 National Insurance Administration, Oslo, Norway.

3 Directorate of Labor Inspection, Oslo, Norway.

4 National Insurance Court, Oslo, Norway.

Reprint requests to: Dr Bente Ulvestad, Cancer Registry of Norway, Institute of Population-based Cancer Research, Montebello, N-0310 Oslo, Norway. [E-mail: bente.ulvestad@kreftregisteret.no] 
explanation for the lack of excess cancer risk was the predominant use of chrysotile in the production process. In other studies of workers of the asbestos-cement producing industry, exposure-dependent increases in mortality rates from respiratory diseases, lung cancer, mesothelioma, and gastrointestinal cancers have been found for cohorts exposed to both chrysotile and crocidolite (9-16). Mesothelioma risk has been strongly related to amphibole exposure, especially exposure to crocidolite (11). However, in a Swedish study of asbestoscement workers with mainly chrysotile exposure (99\%), the risk for pleural mesothelioma was significantly increased (17). Also from other studies, in which exposure to chrysotile fibers dominated, excess mortality from cancer of all sites, lung cancer, and mesothelioma has been reported $(18,19)$. It should be noted, however, that, in most studies, the chrysotile to amphibole ratio is poorly defined.

The aim of our investigation was to study the incidence of cancer among employees of a Norwegian asbestos-cement factory in relation to duration of exposure, time since first exposure, and period of first employment. Results from this Norwegian cohort of asbestos-cement workers have not been published earlier.

\section{Materials and methods}

\section{Factory}

The factory began production during wartime in 1942, manufacturing asbestos-cement sheets. Most of the asbestos (92\%) was chrysotile (20), but for technical reasons a small amount of amphibole (anthophyllite, amosite, or crocidolite) asbestos was always added. Figure 1 shows the annual use of asbestos from 1942 to 1976 according to data obtained from factory records. In addition Finnish asbestos (anthophyllite) was used, but only during wartime from 1942 to 1945, and in small

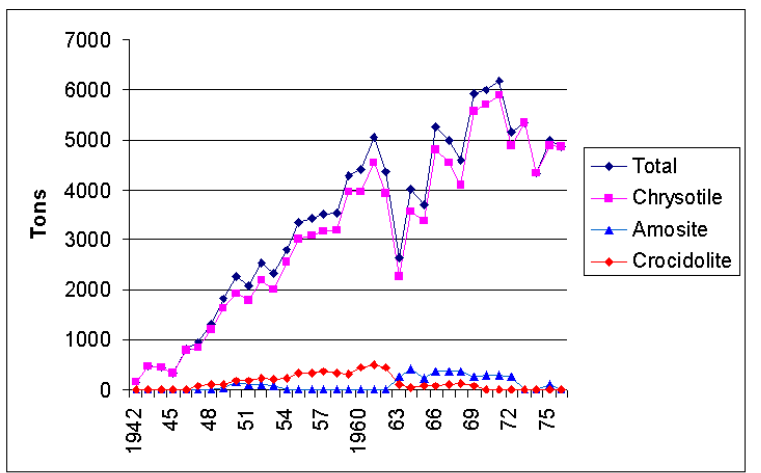

Figure 1. Use of asbestos in the factory in 1942-1976. amounts. Chrysotile was mainly imported from Canada, but also in small amounts from the Soviet Union. By the end of the 1970s the market for asbestos-cement products failed, as they became unpopular in the national construction industry. The factory stopped using asbestos around 1978 and was formally closed in 1980, as it failed to find other fibers to replace asbestos.

\section{Production}

The asbestos arrived in bags of jute up to the beginning of the 1970s, when plastic bags were introduced. Asbestos fibers easily penetrated the intact jute bags. Thus the handling of the bags when they arrived at the factory always involved massive exposure to asbestos. Generally, all workers who did not have crucial functions on the production line that day took part in the unloading and reloading of the asbestos bags in the storeroom. For production the bags were taken from the storeroom and ripped open; the asbestos was then dumped into a mill and crushed to the requested fiber size. Up to 1952, the asbestos was milled dry and was manually handled until it was mixed with water and cement into an asbestos-cement sludge. The sludge was passed on to the asbestos-cement production machinery, where the water was sucked away to produce the final product. In 1952 new milling machinery was introduced, water was added to the milling, and milled asbestos was brought automatically to the asbestos-cement sludge. Even if parts of the production machinery were changed after 1952, the basic production line, machine technology, and formulas did not change very much. However, with the introduction of plastic instead of jute bags in the beginning of the 1970s the asbestos exposure from the handling of the bags decreased substantially.

\section{Exposure}

In 1950,1954 , and 1964, atmospheric particles were measured during the feeding of the mill, after the milling process, and during the feeding of containers with spades in the asbestos store. In 1950 fiber concentrations varying from 3.6 to 70 million particles per cubic foot (mppcf) were recorded (20). On the assumption of an asbestos content of $40-60 \%$ of the total fiber concentration measured (20), this level corresponds roughly to $50-1000$ fibers per milliliter ( $\mathrm{f} / \mathrm{ml}$ ).

In 1954 concentrations between 3.4 and $15.4 \mathrm{mppcf}$ (50-100 f/ml, estimated) were described, with peak exposures of up to $40.5 \mathrm{mppcf}$ ( $600 \mathrm{f} / \mathrm{ml}$, estimated) (20). In 1964 the National Institute of Occupational Health made a survey based on gravimetric measurements and the use of midget impingers. The gravimetric data 
showed concentrations of $0.2-22.8 \mathrm{mg} / \mathrm{m}^{3}$ (20), whereas the corresponding midget impinger results were 5.2-113 mppcf (100-1900 f/ml, estimated).

Systematic efforts to reduce the dust concentrations started in the second half of the 1960s. Respiratory protection devices were introduced at the dustiest spots (during the feeding of the mill and the filling of containers with spades). From 1972 to 1978 the company measured fiber concentrations regularly with personal sampling using the membrane technique. During sacking operations at the mill, fiber concentrations of up to $13 \mathrm{f} / \mathrm{ml}$ were detected, but after 1973 the atmospheric concentrations were generally lower than $5 \mathrm{f} / \mathrm{ml}(20)$.

\section{Cohort and follow-up}

The cohort was restricted to workers who had a minimum of 1 year of employment and who had been hired between 1942 and 1976. In 1976 a list of male workers was compiled from the company files. The total number of workers with a minimum of 1 year of employment was 545 . Four persons were not identified by their personal identification number and were subsequently excluded from the study. A total of $45 \%$ had been employed 10 years or more. Information on smoking habits was collected from the occupational health service for 482 persons. Altogether 355 (65.6\%) were smokers, $49(9 \%)$ were former smokers, $78(14.4 \%)$ were never smokers, and smoking data were missing for 59 (11\%).

\section{Identification of cases}

For the identification of the cancer cases, the cohort was linked to the Cancer Registry of Norway, which has virtually complete records of individual cases of cancer in the Norwegian population since 1 January 1953. The linkage was based on the unique 11-digit personal identification number that was assigned to each person alive in Norway in 1960 or born after that year. The cohort was also linked to Statistics Norway to obtain the date of emigration and the date of death, when relevant. Coding of cancers was based on a modified version of the International Classification of Diseases, 7th revision (ICD-7).

The workers were observed for the incidence of cancer from 1 January 1953, or from 1 year after starting work in the industry after that date, until date of emigration, date of death, or end of follow-up on 31 December 1999, whichever occurred first, giving 17264 person-years of follow-up.

\section{Analysis}

The analysis was based on a comparison between the observed and expected numbers of new cancer cases.
The expected numbers of cases were calculated using the 5-year age- and period-specific incidence rates of cancer of the entire male population in Norway. Standardized incidence ratios (SIR) were calculated as the ratio between the observed and the expected values. The $95 \%$ confidence intervals (95\% CI) of the standardized incidence ratios were estimated on the assumption of a Poisson distribution of the cancer cases. Period of first employment, duration of employment, and time since first employment were used as indicators of exposure, and the calendar-year intervals of the period of first employment were categorized into approximately equally long intervals while also taking into consideration improvements of the work environment.

Poisson regression analysis was used to determine the internal exposure-response relations and for the exploration of potential confounding from smoking. Duration of employment $(<10,10-14, \geq 15$ years) was used as a surrogate variable for exposure. Age was included in the models in four age groups $(<50,50-59,60-69$, $\geq 70$ years). The smoking variables were never smokers, former smokers, current smokers, and unknown. The Epicure statistical package was applied (21).

\section{Results}

During the follow-up 132 workers developed 144 cancers (SIR 1.8, 95\% CI 1.6, 2.2). Table 1 shows the standardized incidence ratios for selected cancers in the total cohort. Lung cancer risk was significantly elevated with

Table 1. Observed numbers of cancer cases and the standardized incidence ratios (SIR) for male workers employed 1 year or more in the Norwegian asbestos-cement factory - follow-up for 1953-1999. (95\% Cl = 95\% confidence interval)

\begin{tabular}{lcrc}
\hline Site $^{\text {a }}$ & Observed (N) & SIR & $95 \% \mathrm{Cl}$ \\
\hline Oral (141,143-148) & 5 & 3.3 & $1.1-7.7$ \\
Stomach (151) & 7 & 1.4 & $0.6-2.9$ \\
Colorectal (153-154) & 17 & 1.6 & $0.9-2.5$ \\
Lung (162) & 33 & 3.1 & $2.1-4.3$ \\
Pleura (163) & 18 & 52.5 & $31.1-83.0$ \\
Prostate (177) & 8 & 0.6 & $0.3-1.1$ \\
Testis (178) & 3 & 2.5 & $0.5-7.3$ \\
Kidney (180) & 4 & 1.3 & $0.4-3.4$ \\
Bladder (181) & 14 & 2.5 & $1.4-4.2$ \\
Melanoma (190) & 5 & 1.5 & $0.5-3.5$ \\
Brain (193) & 6 & 2.4 & $0.9-5.2$ \\
Other sites combined b, c & 24 & 1.2 & $0.8-1.7$ \\
All sites (140-204) & 144 & 1.8 & $1.6-2.2$ \\
\hline a Code of the International Classification of Diseases (7th version) in \\
parentheses. \\
b Other sites combined include lip, liver, pancreas, melanoma, other skin, \\
$\quad$ Hodgkin's and Non-Hodgkin lymphoma, all leukemia, and unspecified. \\
c Basal cell carcinomas are not included.
\end{tabular}

Scand J Work Environ Health 2002, vol 28, no 6 
33 observed cases versus 10.7 expected. Risk of pleural neoplasms, all of which were malignant mesotheliomas, was highly elevated. No peritoneal mesothelioma was found. The ratio of mesothelioma to lung cancer cases was 1:2 for the total cohort. The risk of colorectal cancer was elevated for workers with more than 3 years of employment (SIR 1.8, 95\% CI 1.1-2.9) (not shown in table). Of the 17 colorectal cancers $12(70.6 \%)$ were rectal cancers (SIR 2.9, 95\% CI 1.5-5.0) (not shown in table). The risks of cancer of the buccal cavity and pharynx (oral cancer) and bladder cancer were also elevated with standardized incidence ratios of 3.3 and 2.5 , respectively.

Table 2 shows the risk of malignant mesothelioma and lung cancer by increasing duration of employment. Among the workers employed 5 years or more, the risk of malignant mesothelioma was elevated. The standardized incidence ratio was highest for the workers employed 15 years or more. Lung cancer was elevated for workers employed 1-4 years and for those with 15 or more years of employment. Lung cancer was observed for three never smokers and one ex-smoker.

Table 2. Observed and expected numbers of malignant mesothelioma and lung cancer cases and the standardized incidence ratios (SIR) with the $95 \%$ confidence intervals $(95 \% \mathrm{Cl})$ for the male workers employed $\geq 1$ year in the Norwegian asbestos-cement factory — followup for 1953-1999.

\begin{tabular}{|c|c|c|c|c|c|c|c|c|}
\hline \multirow[b]{2}{*}{ Duration of employment } & \multicolumn{4}{|c|}{ Malignant mesothelioma } & \multicolumn{4}{|c|}{ Lung cancer } \\
\hline & $\begin{array}{l}\text { Observed } \\
\text { (N) }\end{array}$ & $\begin{array}{l}\text { Expected } \\
\text { (N) }\end{array}$ & SIR & $95 \% \mathrm{Cl}$ & $\begin{array}{l}\text { Observed } \\
\text { (N) }\end{array}$ & $\begin{array}{l}\text { Expected } \\
\text { (N) }\end{array}$ & SIR & $95 \% \mathrm{Cl}$ \\
\hline $1-4$ years & - & 0.07 & 0.0 & .. & 9 & 2.1 & 4.4 & $2.0-8.3$ \\
\hline $5-9$ years & 2 & 0.06 & 34.8 & $4.2-126$ & 4 & 1.7 & 2.3 & $0.6-5.9$ \\
\hline $10-14$ years & 3 & 0.06 & 51.3 & $10.6-149$ & 4 & 1.8 & 2.3 & $0.6-5.8$ \\
\hline$\geq 15$ years & 13 & 0.16 & 84.1 & $44.8-144$ & 16 & 5.2 & 3.1 & $1.8-5.0$ \\
\hline
\end{tabular}

Table 3. Observed number of cases and the standardized incidence ratios (SIR) with the $95 \%$ confidence intervals (95\% CI) for malignant mesothelioma among the male workers with $\geq 1$ year of employment in the Norwegian asbestos-cement factory, by period of first employment in the factory and time since first employment — follow-up for 1953-1999.

\begin{tabular}{|c|c|c|c|c|c|c|c|c|c|c|c|c|}
\hline \multirow{3}{*}{$\begin{array}{l}\text { Period of first } \\
\text { employment }\end{array}$} & \multicolumn{12}{|c|}{ Time since first employment } \\
\hline & \multicolumn{3}{|c|}{$0-14$ years } & \multicolumn{3}{|c|}{$15-29$ years } & \multicolumn{3}{|c|}{$\geq 30$ years } & \multicolumn{3}{|c|}{ Total } \\
\hline & $\begin{array}{l}\text { Observed cases } \\
\text { (N) }\end{array}$ & SIR & $95 \% \mathrm{Cl}$ & $\begin{array}{l}\text { Observed cases } \\
\text { (N) }\end{array}$ & $\mathrm{SIR}$ & $95 \% \mathrm{Cl}$ & $\begin{array}{l}\text { Observed cases } \\
\text { (N) }\end{array}$ & SIR & $95 \% \mathrm{Cl}$ & $\begin{array}{l}\text { Observed cases } \\
\text { (N) }\end{array}$ & SIR & $95 \% \mathrm{Cl}$ \\
\hline $1942-1951$ & - &.$\cdot$ & .. & 1 & 58.0 & $1.5-323$ & 11 & 108.3 & $54.0-194$ & 12 & 99.0 & $51.3-173$ \\
\hline 1952-1959 & - &.$\cdot$ & .. & 1 & 45.2 & $1.1-252$ & 2 & 33.6 & $4.1-121$ & 3 & 35.3 & $7.3-103$ \\
\hline $1960-1969$ & - & .. & .. & 2 & 36.7 & $4.5-133$ & 1 & 22.4 & $0.6-125$ & 3 & 27.9 & $5.8-81.6$ \\
\hline $1970-1975$ & - & .. & .. & - &.$\cdot$ & $\cdot \cdot$ & - & $\cdot \cdot$ & $\cdot \cdot$ & - & $\cdot$. & $\cdot \cdot$ \\
\hline Total & - & .. & .. & 4 & 34.6 & $9.4-88.6$ & 14 & 68.0 & $37.2-114$ & 18 & 52.5 .4 & $31.1-83.0$ \\
\hline
\end{tabular}

Table 4. Observed number of cases and the standardized incidence ratios (SIR) with the $95 \%$ confidence intervals $(95 \% \mathrm{CI})$ for lung cancer among the male workers with $\geq 1$ year of employment in the Norwegian asbestos-cement factory, by period of first employment in the factory and time since first employment — follow up for 1953-1999.

\begin{tabular}{|c|c|c|c|c|c|c|c|c|c|c|c|c|}
\hline \multirow{3}{*}{$\begin{array}{l}\text { Period of first } \\
\text { employment }\end{array}$} & \multicolumn{12}{|c|}{ Time since first employment } \\
\hline & \multicolumn{3}{|c|}{$0-14$ years } & \multicolumn{3}{|c|}{$15-29$ years } & \multicolumn{3}{|c|}{$\geq 30$ years } & \multicolumn{3}{|c|}{ Total } \\
\hline & $\begin{array}{l}\text { Observed cases } \\
(\mathrm{N})\end{array}$ & SIR & $95 \% \mathrm{Cl}$ & $\begin{array}{l}\text { Observed cases } \\
\text { (N) }\end{array}$ & $\mathrm{SIR}$ & $95 \% \mathrm{Cl}$ & $\begin{array}{l}\text { Observed cases } \\
\text { (N) }\end{array}$ & SIR & $95 \% \mathrm{Cl}$ & $\begin{array}{l}\text { Observed cases } \\
\text { (N) }\end{array}$ & $\operatorname{SIR}$ & $95 \% \mathrm{Cl}$ \\
\hline $1942-1951$ & 1 & 10.0 & $0.3-55.8$ & 7 & 7.6 & $3.1-15.6$ & 11 & 3.5 & $1.7-6.2$ & 19 & 4.5 & $2.7-7.1$ \\
\hline $1952-1959$ & - & .. & .. & 2 & 2.2 & $0.3-7.9$ & 1 & 0.6 & $0.1-3.6$ & 3 & 1.1 & $0.2-3.3$ \\
\hline $\begin{array}{l}1960-1969 \\
1970-1975\end{array}$ & - & $\ddot{6} 6.5$ & 0.8-23.6 & $\begin{array}{l}4 \\
3\end{array}$ & $\begin{array}{l}2.5 \\
5.4\end{array}$ & $\begin{array}{l}0.7-6.5 \\
1.1-15.8\end{array}$ & $\begin{array}{l}2 \\
-\end{array}$ & $\begin{array}{l}1.9 \\
\cdots\end{array}$ & $\begin{array}{c}0.2-6.9 \\
. .\end{array}$ & $\begin{array}{l}6 \\
5\end{array}$ & $\begin{array}{l}2.0 \\
5.8\end{array}$ & $\begin{array}{l}0.7-4.4 \\
1.9-13.6\end{array}$ \\
\hline Total & 3 & 3.2 & $0.7-9.4$ & 16 & 4.0 & $2.3-6.5$ & 14 & 2.4 & $1.3-4.1$ & 33 & 3.1 & $2.1-4.3$ \\
\hline
\end{tabular}


In tables 3 and 4 (on page 414) the risk of malignant mesothelioma and lung cancer are shown by period of first employment and time since first employment. The workers employed before 1952, when dry milling was performed, had the highest incidence of mesothelioma (SIR 99.0, 95\% CI 51.3-173). However, the risk of mesothelioma was very high even among workers employed after 1952 (table 3). No case of malignant mesothelioma was found among those with less than 15 years since first employment. In the groups with 15-29 years and $\geq 30$ years since first employment, the standardized incidence ratios were 34.6 (based on 4 cases) and 68.0 (based on 14 cases), respectively.

The highest significant risk of lung cancer was found for the workers first employed between 1942 and 1951 and with 15-29 years since first employment (SIR 7.6, 95\% CI 3.1-15.6) (table 4). However, among the workers first employed in 1970-1975 and with 15-29 years since first employment, three cases of lung cancer were observed (SIR 5.4, 95\% CI 1.1-15.8). No trend according to period of first employment or time since first employment was found.

The risk of bladder cancer was significantly elevated (SIR 3.3, 95\% CI 1.5-6.2) among the workers with $\geq 15$ years of employment (not shown in table). The highest incidence of bladder cancer was found for the workers first employed between 1952 and 1959 (SIR 3.6, 95\% CI 1.2-8.5) (not shown in table). Oral cancer or cancers of the colon or rectum were not associated with the duration of employment, the period of first employment, or the time since first employment.

In the internal analysis an association was found between the risk of mesothelioma and the duration of employment (table 5). We also investigated the potential associations between duration of employment and lung cancer or bladder cancer, but found no associations.

\section{Discussion}

This study of asbestos-cement workers demonstrated an elevated risk of cancer at all sites, mainly due to excess risks of malignant mesothelioma, lung cancer, oral cancer, colorectal cancer, and bladder cancer.

The study had several design features that ensured its validity. The use of personal identification numbers facilitated the identification and linkage to the cancer data of the Cancer Registry of Norway, which is considered to have complete data. The cohort was small, but only $0.7 \%$ of the workers employed 1 year or more were lost to follow-up, and the follow-up period was long, with a minimum of 20 years since last exposure. Furthermore, the cohort contained many long-term employees, as $45 \%$ were employed 10 years or more.
Table 5. Poisson regression analysis of mesothelioma and lung cancer risk by duration of employment, controlled for age and smoking. ( $95 \% \mathrm{Cl}=95 \%$ confidence interval)

\begin{tabular}{|c|c|c|c|c|}
\hline \multirow{2}{*}{ Variable } & \multicolumn{2}{|c|}{ Mesothelioma } & \multicolumn{2}{|c|}{ Lung cancer } \\
\hline & Rate ratio & $95 \% \mathrm{Cl}$ & Rate ratio & $95 \% \mathrm{Cl}$ \\
\hline \multicolumn{5}{|c|}{ Duration of employment } \\
\hline$<10$ years & 1.0 & .. & 1.0 & .. \\
\hline $10-14$ years & 4.3 & $0.7-28.1$ & 0.7 & $0.2-\quad 2.2$ \\
\hline$\geq 15$ years & 6.7 & $1.3-34.3$ & 0.9 & $0.4-\quad 2.0$ \\
\hline \multicolumn{5}{|l|}{ Age } \\
\hline$<50$ years & 1.0 & .. & 1.0 & .. \\
\hline $50-59$ years & 0.8 & $0.07-9.2$ & 7.7 & $2.0-29.8$ \\
\hline $60-69$ years & 13.1 & $2.7-64.3$ & 13.5 & $3.5-51.3$ \\
\hline$\geq 70$ years & 7.3 & $1.1-48.2$ & 47.0 & $12.8-173$ \\
\hline \multicolumn{5}{|l|}{ Smoking } \\
\hline Never smokers & 1.0 & .. & 1.0 & .. \\
\hline Smokers & 1.0 & $0.3-3.5$ & 2.4 & $0.7-\quad 7.9$ \\
\hline Former smokers & 1.0 & $0.2-6.0$ & 0.6 & $0.1-\quad 5.3$ \\
\hline Unknown & 2.1 & $0.2-22.5$ & 1.8 & $0.3-11.0$ \\
\hline
\end{tabular}

While detailed individual work histories and reliable exposure measurements with which to estimate cumulative exposure were lacking, the description of the work conditions indicated that all the workers may have experienced considerable exposure to asbestos. The heaviest exposure probably occurred before 1952, when dry milling was performed. Stationary sampling at the most exposed spots suggested that the atmospheric concentrations were also extremely high throughout the 1950s and 1960s. In the 1970s, dust was regularly measured, and the levels were estimated to range between 1 and $13 \mathrm{f} / \mathrm{ml}$, mostly below $5 \mathrm{f} / \mathrm{ml}$. Although such historical measurements should be interpreted with caution, these estimates appear high compared with reports from other asbestos cement plants $(4,6,7,17,19)$.

\section{Respiratory system}

The highest risk of pleural mesothelioma was found among the workers employed before 1952. No mesothelioma case was found among those with less than 5 years of employment. The highest risk was found for the workers with more than 15 years of employment, and a clear dose-response relationship was seen when duration of employment was used as an indicator of dose. However, the fact that the duration of employment is strongly associated with latency makes it impossible in this study to decide if the mesothelioma risk was determined mainly by time since first exposure or by dose. Other studies have shown that mesothelioma risk is determined mainly by time since first exposure, secondly by dose (22). The very high risk of mesothelioma, compared with the moderate increase in lung cancer, produced an unusually high mesothelioma-to-lung cancer ratio. 
Mesothelioma has mainly been associated with exposure to amphiboles (23). Chrysotile, mainly imported from Canada, has been the major type of asbestos $(>90 \%)$ in the Norwegian plant. Several studies have been published on Canadian chrysotile miners and millers, for whom high pulmonary levels of tremolite fibers have been detected in the lungs (24). Low levels of amosite and crocidolite have been found in the lungs of Canadian asbestos workers (25). In the Norwegian plant, around $8 \%$ amphiboles were added to the asbestos-cement production to promote the withdrawal of water from the product at the end of the production line. Gylseth et al (20) studied fiber type and concentration in the lungs of workers of the Norwegian asbestos-cement factory. The percentage of chrysotile asbestos in the lung tissue varied between $0 \%$ and $9 \%$, whereas the corresponding numbers for the amphiboles were $76 \%$ and 99\%. Exposure to amphiboles (crocidolite, amosite) and contaminated chrysotile (tremolite, crocidolite, amosite) may therefore explain the high mesothelioma risk.

Also in other countries, chrysotile has dominated in asbestos-cement products, and many studies of asbestos-cement workers report negative results (5-8). A Swedish study, however, reported elevated risk for pleural mesothelioma among asbestos-cement workers with predominantly chrysotile exposure (17), but also in the Swedish study exposure to amphiboles may have occurred in all cases. Excess mortality from lung cancer and mesothelioma has also been reported from other studies, in which the exposure to chrysotile fibers has dominated $(18,19)$. In our study we could not rule out the possibility that chrysotile contributed to the excess cancer risk.

The extensive focus on the asbestos-cement industry that occurred in the late 1970s may have biased the observed relationship between asbestos exposure and mesothelioma. Thirteen of the eighteen mesothelioma cases were diagnosed after 1980. Subjects working with asbestos may be more likely to have a tumor diagnosed as mesothelioma than persons in nonasbestos exposed cohorts (26), and a diagnostic bias cannot be excluded although $94 \%$ and $90 \%$ of mesothelioma and lung cancer cases were histologically verified at the population level (27).

Cigarette smoking has little or no effect on the incidence rates of mesothelioma, unlike its influence on lung cancer (28). The risk of lung cancer was highest among the workers employed before 1952, but the incidence of lung cancer did not increase with the duration of employment, nor was a trend shown according to time since first employment. The observed lack of dose-response is in accordance with previous studies in the asbestos-cement industry with duration of exposure as a dose surrogate $(15,17,29)$, and it can be considered an indication of a weaker association between asbestos exposure and lung cancer as compared with malignant mesothelioma. The cohort contained only $14.4 \%$ never smokers, and this finding indicates that the cohort had more tobacco use than did the entire male population of Norway, which was used as the control group. It is a bit surprising that, in this heavily smoking cohort with obvious heavy asbestos exposure, no more lung cancers were found.

\section{Other types of cancer}

No peritoneal mesothelioma was found. It has been suggested that peritoneal mesotheliomas are linked to intense and prolonged exposure (23). In the present study, in which $45 \%$ of the workers were employed 10 years or more and fiber measurements indicated a considerable exposure to asbestos, the lack of peritoneal mesotheliomas was in contrast with this notion.

The standardized incidence ratio of colorectal cancer was elevated for the workers with more than 3 years of employment. Some epidemiologic studies have found an excess of gastrointestinal carcinomas among asbestos workers, and the authors have reported indications of an increased risk of colorectal cancer especially (10, 17, 30-32). However, the association between asbestos exposure and gastrointestinal cancer is not definite. In our study no association with duration of employment, time since first employment, or period of first employment was found for colorectal cancer. A predominance of rectal cancer was found, in contrast to the findings of Jakobsson et al (33), among Swedish asbestos-cement workers.

The standardized incidence ratio for oral cancer was also elevated. Several investigators have reported an association between asbestos exposure and laryngeal carcinoma but, as far as we know, not with oral cancer. No association with duration of employment, time since first employment or period of first employment was seen. We have no information on alcohol consumption and only limited information on smoking habits, and a possible effect from these known confounders could not be ruled out.

An excess risk of bladder cancer in association with asbestos exposure has, as far as we know, not been demonstrated earlier. Smoking is a known risk factor for bladder cancer, but a standardized incidence ratio of 2.5 (95\% CI 1.4-4.2) can hardly be explained by smoking alone. Studies have identified the presence of asbestos fibers, both amphibole and chrysotile, in human urine samples $(34,35)$.

In conclusion, our study showed a high incidence of mesothelioma and a high ratio of mesothelioma to lung cancer among workers exposed to a $92 \%$ chrysotile and $8 \%$ crocidolite-amosite mix of asbestos fibers. The association between lung cancer and asbestos exposure 
seemed to be weaker than for malignant mesothelioma. In addition, there was an increased incidence of oral cancer, colorectal cancer, and bladder cancer in the cohort with unknown association to asbestos exposure.

\section{References}

1. Doll R. Mortality form lung cancer in asbestos workers. Br J Ind Med 1955;12:81-6.

2. Wagner JC, Sleggs CA, Marchand P. Diffuse pleural mesothelioma and the asbestos exposure in the North Western Cape Province. Br J Ind Med 1960;17:260-71.

3. Selikoff IJ, Churg J, Hammond EC. Asbestos exposure and neoplasia. JAMA 1964;188:22-6.

4. Finkelstein M. Asbestosis in long-term employees of an Ontario asbestos-cement factory. Am Rev Respir Dis 1982;125:496-501.

5. Thomas HF, Benjamin IT, Elwood PC, Sweetnam PM. Further follow-up study of workers from an asbestos cement factory. Br J Ind Med 1982;39:273-6.

6. Ohlson CG, Hogstedt C. Lung cancer among asbestos cement workers: a Swedish cohort study and a review. Br J Ind Med 1985;42:397-402.

7. Gardner MJ, Winter PD, Pannett B, Powell CA. Follow up study of workers manufacturing chrysotile asbestos cement products. Br J Ind Med 1986;43:726-32.

8. Lacquet LM, Van der Linden L, Lepoutre J. Roentgenographic lung changes, asbestosis and mortality in a Belgian asbestos-cement factory. In: Wagner JC, editor. Biological effects of mineral fibers. Lyon: IARC, 1980. Scientific publications, no 30.

9. Neuberger M, Kundi M. Individual asbestos exposure: smoking and mortality - a cohort study in the asbestos cement industry. Br J Ind Med 1990;47:615-20.

10. Finkelstein M. Mortality among long-term employees of an Ontario asbestos-cement factory. Br J Ind Med 1983;40:13844.

11. Weill H. Biological effects: asbestos-cement manufacturing. Ann Occup Hyg 1994;38:533-8.

12. Hughes JM, Weill H, Hammad YY. Mortality of workers employed in two asbestos cement manufacturing plants. Br J Ind Med 1987;44:161-74.

13. Belli S, Bruno C, Comba P, Grignoli M. Cause-specific mortality of asbestos-cement workers compensated for asbestosis in the city of Bari. Epidemiol Prev 1998;22:8-11.

14. Botta M, Magnani C, Terracini B, Bertolone GP, Castagneto $\mathrm{B}$, Cocito V, et al. Mortality from respiratory and digestive cancers among asbestos cement workers in Italy. Cancer Detect Prev 1991;15:445-7.

15. Alies-Patin AM, Valleron AJ. Mortality of workers in a French asbestos cement factory 1940-1982. Br J Ind Med 1985;42:219-25.

16. Szeszenia-Dabrowska N, Wilczynska U, Szymczak W.
Cancer risk in asbestos-cement industry workers in Poland. Med Pr 1997;48:473-83.

17. Albin M, Jakobsson K, Attewell R, Johansson L, Welinder $\mathrm{H}$. Mortality and cancer morbidity in cohorts of asbestos cement workers and referents. Br J Ind Med 1990;47:60210.

18. Tulchinsky TH, Ginsberg GM, Iscovich J, Shihab S, Fischbein A, Richter ED. Cancer in ex-asbestos cement workers in Israel, 1953-1992. Am J Ind Med 1999;35:1-8.

19. Raffn E, Villadsen E, Engholm G, Lynge E. Lung cancer in asbestos cement workers in Denmark. Occup Environ Med 1997;54:143.

20. Gylseth B, Mowe G, Wannag A. Fiber type and concentration in the lungs of workers in an asbestos cement factory. $\mathrm{Br}$ J Ind Med 1983;40:375-9.

21. Preston D, Lubin J, Pierce D, McConney M. Epicure user's guide. Seattle (WA): Hirosoft International Corporation 1993.

22. Peto J, Seidman H, Selikoff IJ. Mesothelioma mortality in asbestos workers: implications for models of carcinogenesis and risk assessment. Br J Cancer 1982;45:124-35.

23. Britton M. The epidemiology of mesothelioma. Semin Oncol 2002;29:18-25.

24. Case BW, Dufresne A. Asbestos, asbestosis, and lung cancer: observations in Quebec chrysotile workers. Environ Health Perspect 1997;105 Suppl 5:1113-9.

25. Green FH, Harley R, Vallyathan V, Althouse R, Fick G, Dement J, et al. Exposure and mineralogical correlates of pulmonary fibrosis in chrysotile asbestos workers. Occup Environ Med 1997:54:549-59.

26. Attanoos RL, Gibbs AR. Primary malignant gonadal mesotheliomas and asbestos. Histopathology 2000;37:150-9.

27. Hansen S, Langballe EM, Norstein J, Næss A. Cancer in Norway 1999. Oslo: Cancer Registry of Norway, 2002.

28. Hammond EC, Selikoff IJ, Seidman H. Asbestos exposure, cigarette smoking and death rates. Ann NY Acad Sci 1979;330:473-90.

29. Raffn E, Lynge E, Juel K, Kongsgaard B. Incidence of cancer and mortality among employees in the asbestos cement industry in Denmark. Br J Ind Med 1989;45:283-91.

30. Selikoff IJ, Hammond EC, Seidman H. Mortality experience of insulation workers in the United States and Canada, 19431976. Ann NY Acad Sci 1979;330:91-116.

31. McDonald JC, Lidell FDK, Gibbs GW, Eyssen GE, McDonald AD. Dust exposure and mortality in chrysotile mining, 1910-75. Br J Ind Med 1980;37:11-24.

32. Enterline PE, Hartley J, Henderson V. Asbestos and cancer: a cohort followed up to death. Br J Ind Med 1987;44:396-401.

33. Jakobsson K, Albin M, Hagmar L. Asbestos, cement, and cancer in the right part of $\mathrm{t}$ he colon. Occup Environ Med 1994;51:95-101.

34. Cook PM, Olson GF. Ingested mineral fibers: elimination in human urine. Science 1979;204:195-8.

35. MB, Hallenbeck WH. Detection of chrysotile in workers' urine. Ann Ind Hyg 1985;29:305-35.

Received for publication: 19 July 2002 